\title{
Racial Socialization as a Mechanism for Positive Development Among African American Youth
}

\author{
Ashley B. Evans, ${ }^{1}$ Meeta Banerjee,${ }^{2}$ Rika Meyer, ${ }^{1}$ Adriana Aldana, ${ }^{1}$ Monica Foust, ${ }^{1}$ \\ and Stephanie Rowley ${ }^{1}$ \\ ${ }^{1}$ University of Michigan and ${ }^{2}$ Michigan State University
}

ABSTRACT_This review considers the relation between racial socialization and positive youth development in African American families. A central premise is that positive youth outcomes (competence, confidence, character, connection, and caring) are often directly supported through traditional racial socialization messages (such as cultural socialization, preparation for bias, self-worth, and egalitarianism). The review draws contrasts between the more prevalent risk and resilience models and positive youth development, and makes recommendations for future research directions.

KEYWORDS-positive youth development; racial socialization; African American youth

As a theoretical framework, positive youth development (PYD) provides a refreshing perspective on the social and emotional development of youth. Rather than focusing on the risks associated with development, PYD promotes the study of "what is going right" (Morrissey \& Werner-Wilson, 2005, p. 67), emphasizing personal assets and positive engagement (Larson, 2000). PYD may also include prosocial behavior, belief in the future, and spirituality. This perspective stands in contrast to traditional notions of success. An adolescent may be a good student and stay out of trouble, but may lack the skills needed to thrive as an adult and become an active citizen (Catalano, Berglund, Ryan, Lonczak, \& Hawkins, 2002). PYD emphasizes that all youth are capable of thriving if they are supported by contexts that provide

Correspondence concerning this article should be addressed to Ashley B. Evans, Department of Psychology, University of Michigan, Ann Arbor, MI 48109-1043; e-mail: ashleye@umich.edu.

(c) 2012 The Authors

Child Development Perspectives ๑ 2012 The Society for Research in Child Development DOI: $10.1111 / \mathrm{j} \cdot 1750-8606.2011 .00226 . x$ opportunities for developing their unique skills and strengths (Damon, 2004).

Despite the fact that these features make the approach particularly relevant for African American children, whose development researchers often view from a deficit perspective (McLoyd, 2006), very little research has addressed the importance of PYD in this population. Moreover, PYD studies rarely consider culture-specific assets such as racial identity, the larger African American community, or parents' racial socialization (Catalano et al., 2002). The predominant literature on youth of color places them within a discourse on "at-risk" populations, emphasizing pathology and failure (Hagen, Pacynski, Sprang, Torvinen, \& Petiprin, 2010; McLoyd, 2006). Although resiliency research has led to a focus on protective attributes in both youth and families, the reduction or prevention of negative outcomes does not equate to positive development. Further, although considerations of family factors important for positive outcomes is an explicit focus on much of the work on resilience (e.g., Masten \& Coatsworth, 1998), those family processes unique to ethnic minority families have not received sufficient attention in this research. Thus, we are left with little insight into normative processes leading to PYD in African American youth.

We begin with a brief review of the literature on PYD among African American youth. Then we discuss the potential role of families as promoters of PYD in these youth's lives. Finally, we discuss some additional considerations essential to reframing our research agendas in terms of PYD among youth of color.

\section{POSITIVE DEVELOPMENT OF AFRICAN AMERICAN YOUTH}

African American youth are more likely to experience risk factors such as poverty, single-parent households, and residence in communities with few resources, all of which could adversely affect their development (Ceballo \& McLoyd, 2002; McLoyd, 1990). In a survey of research on African American youth, 
Hagen et al. (2010) found that most studies examined negative outcomes, whereas research in the same journals on European American or Asian American youth tended to examine either normative development or positive outcomes. Although this trend has declined significantly since McLoyd and Randolph (1985) first noted it, there is still a need to move beyond deficit-focused research.

Risk and resilience models certainly highlight personal and cultural factors that protect African American youth from some of the negative effects of their environments. However, these models begin the narrative of their lives with the negative, overlooking the normative development of positive characteristics. One central goal here is to identify and highlight family factors that may be particularly relevant for the promotion of developmental assets among these youth.

Several scholars have proposed that despite differences in contextual assets, all young people have individual resources that are pertinent to their positive development (McAdoo, 1999; Taylor, 2001). Some models of PYD refer to these individual competencies as developmental assets - the building blocks that enhance and promote healthy development (Scales, Benson, Leffert, \& Blyth, 2000). Nevertheless, current models of PYD have not always appropriately attended to differences in context that may influence development. In particular, PYD models fail to articulate the role of race and ethnicity for positive youth outcomes in families of color. Furthermore, current interventions that highlight PYD outcomes have not focused on the role of family processes or cultural factors that may play a role in these children's development.

A number of developmental assets related to race and ethnicity are unique to youth of color. For example, among African American youth, racial identity is positively related to self-esteem (Rowley, Sellers, Chavous, \& Smith, 1998; Sellers, Copeland-Linder, Martin, \& Lewis, 2006) and academic achievement (Jagers, Smith, Mock, \& Dill, 1997). However, few studies beyond the literature on racial identity have recognized the relation of these cultural assets to positive developmental outcomes outside of a risk-based perspective.

External assets that may uniquely enrich African American youth development include families, peers, and community systems such as churches. African American parents identified church as a positive component to the academic success of their sons (Maton, Hrabowski, \& Greif, 1998). Furthermore, the family is an important factor in their development. For example, African American youth's ethnic identities are largely shaped by racial socialization that families provide (Neblett, Smalls, Ford, Nguyên, \& Sellers, 2009). However, few studies examine how family processes contribute to the development of positive assets.

\section{FAMILIES AND PYD}

PYD perspectives emphasize the person-in-environment approach, noting that competencies develop in the context of social relationships (Catalano et al., 2002). However, the field has largely overlooked the potential input of families. One of the most comprehensive reviews of the effectiveness of PYD interventions found that nearly all of these efforts included a school component, but only $60 \%$ included families (Catalano et al., 2002). Those interventions that included families combined family and school settings, yielding less insight into the family processes associated with PYD. There has been little focus on how the developmentpromoting characteristics of families affect PYD in African Americans (Tolan, Sherrod, Gorman-Smith, \& Henry, 2004). Families are likely to provide opportunities to develop the competencies associated with PYD. We are not suggesting that parenting and other family processes have not been related to positive outcomes including self-esteem, academic achievement, and psychological well-being-only that families are typically unrepresented in research using the PYD framework.

Likewise, although PYD perspectives emphasize social contexts and relationships, there has been little attention to culturespecific processes involved in developing assets. Garcia Coll et al. (1996) note the importance of race, ethnicity, and culture to family processes. They suggest that social stratification in the form of prejudice, racism, and discrimination directly and indirectly affects parent socialization and child outcomes. Moreover, their conceptualization of adaptive culture includes family or group traditions, cultural legacies, and racial socialization, which they consider to be a central role of families. They suggest that these cultural factors relate directly to children's developmental outcomes, which would include positive youth outcomes. Thus, there is considerable theoretical evidence that racial socialization is key to successful child outcomes.

\section{RACIAL SOCIALIZATION AND PYD}

We chose to consider the role of racial socialization in the development of PYD for a number of reasons. First, qualitative studies show that African American parents often report telling their children that being a good person and working hard are of critical importance to being Black (Suizzo, Robinson, \& Pahlke, 2008). That is, some African American parents view positive youth outcomes as part and parcel to their race-related socialization agenda.

Second, some aspects of racial socialization, such as cultural socialization, include lessons about role models that embody positive characteristics, such as leadership, character, and civic engagement (Hughes et al., 2006). African American parents may feel that providing these race-related messages to their children will inspire their children to become active participants within their community and engage in social action and change.

Third, racial socialization may raise awareness of injustice and offer examples of social agitation that may connect with adolescents' developing sense of agency and prosocial attitudes. Many African American parents report that they shared stories of the Civil Rights Movement or of African American political 
figures (Hughes et al., 2006). These processes may mirror those used by community-based youth programs that foster racial consciousness and result in positive outcomes for children of color. Research on intergroup dialogues with youth from diverse racial and ethnic backgrounds, for example, shows that racial socialization-in the form of group dialog about issues of race, culture, privilege, and power-influences positive youth outcomes, including increased in-group exploration, greater tolerance for other groups, reductions in prejudice and stereotyping, increased likelihood that participants will stand up against discrimination, and increased caring for others (Checkoway, 2009; Spencer, Brown, Griffin, \& Abdullah, 2008). In addition, multiculturalism in school-based programs increases youth's capacity to build friendships across racial boundaries and their understanding of their personal role in breaking down racial barriers (Nagda, 2006).

Unfortunately, research linking racial socialization and positive youth outcomes is scant, and conceptual frameworks to support such linkages are underdeveloped (Hughes et al., 2006). However, a growing amount of scholarship points to positive effects of racial socialization on the health and wellbeing of African American youth (Harris-Britt, Valrie, KurtzCostes, \& Rowley, 2007; Hughes et al., 2006). In the following sections, we describe some of the literature illustrating the connection between racial socialization practices and PYD outcomes.

\section{DIMENSIONS OF PYD}

Lerner et al. (2005) formulated and validated one of the most widely used frameworks of PYD, the "five Cs"-competence, confidence, character, connection, and caring. Lerner et al. defined competence as an individual's view of her or his actions in different domains such as social, academic, cognitive, and vocational. An individual with high social competence may excel at interpersonal skills, whereas an individual with high cognitive competence would exhibit the ability to solve problems and make decisions. Academic grades, attendance, and test scores are part of academic competence, whereas vocational competence involves work habits and career choice explorations. Confidence refers to the individual's overall sense of positive self-worth and self-efficacy (Lerner, 2004). A child with high levels of confidence would display high self-esteem and positive self-efficacy in different areas. Character encompasses respecting societal and cultural rules or norms, a sense of right and wrong, and integrity (Roth \& Brooks-Gunn, 2003). The fourth $\mathrm{C}$, connection, is exemplified in the creation of positive bonds with people and institutions through bidirectional exchanges with peers, family, school, or communities (Lerner, 2004). Finally, caring refers to the sense of sympathy and empathy for others (Lerner et al., 2005). We relate racial-ethnic socialization dimensions to the five themes represented in most other PYD frameworks.
In the following section, we use current research to demonstrate relations between racial socialization and PYD. In addition, given the sparse nature of this literature, we also use research on racial socialization to hypothesize about potential connections that future research should explore.

\section{RELATING RACIAL SOCIALIZATION TO PYD}

Hughes et al. (2006) identified three dimensions of racial-ethnic socialization that have been related to positive outcomes in African American youth: cultural socialization, preparation for bias, and egalitarianism.

Hughes and Johnson (2001) defined cultural socialization as messages and practices that teach children about racial-ethnic heritage and provide the child with a sense of racial-ethnic pride. These practices can include celebrating cultural holidays such as Kwanzaa to underscore its importance or talking about important figures in African American history.

Research on cultural socialization has been linked to positive youth outcomes within the areas of competence, connection, and caring (Caughy, O'Campo, Randolph, \& Nickerson, 2002; Hughes, Witherspoon, Rivas-Drake, \& West-Bey, 2009). Several scholars have examined both direct and indirect effects of racial socialization on academic outcomes (Hughes et al., 2009; Neblett, Philip, Cogburn, \& Sellers, 2006). One such study found direct, positive links between racial socialization and academic efficacy. Youth who reported more cultural socialization reported feeling more confident about their ability to manage their academic success (Hughes et al., 2009). Another study showed that African American children who resided in homes with more African cultural artifacts and toys had stronger cognitive skills (Caughy et al., 2002). Studies on racial socialization have also found a relation between cultural socialization and racial identity, which we suggest falls under connection as racial identity reflects a sense of shared experience. The literature in this area has found that children report a positive racial identity when their parents provide them with messages about racial pride or cultural heritage (Stevenson, 1995). Moreover, cultural socialization, including messages from parents, was found to be positively linked to self-esteem among African American adolescents (Harris-Britt et al., 2007).

Thus, current research demonstrates that cultural socialization can be linked to child outcomes related to competence, connection, and confidence. Additional research will likely show connections to a number of other areas of PYD. For example, youth who are told stories of the Civil Rights Movement may also have greater character and caring. They may be more likely to be civically engaged and more willing to stand up for their own and others' rights.

Preparation for bias is defined as not only providing children with messages about racial barriers or awareness of racism but also providing coping mechanisms to deal with those barriers (Hughes \& Chen, 1997). For African American families, this 
could include messages that emphasize working twice as hard as Whites to reap the same rewards or teaching children how to counter racial stereotypes.

Results have been mixed for studies on the relation between preparation for bias socialization and African American youth outcomes. For example, preparation for bias messages has been positively related to academic competence in samples of African American youth (Bowman \& Howard, 1985; Sanders, 1997). However, Marshall (1995) found that African American children who received more preparation for bias messages had lower reading scores. Marshall suggested that was possible that children who were already displaying lower competencies in reading had parents who were then providing messages about preparation for bias or vice versa. Thus, longitudinal research in this area is needed. Interestingly, although the findings on preparation for bias have been mixed for academic competence, it has been positively linked to aspects of the parent-child relationship, an aspect of connection. One study found that their measure of preparation for bias was positively related to parent and child positivity in a sample of African American parent-child dyads (Frabutt, Walker, \& MacKinnon-Lewis, 2002), suggesting that parents who provide their children with messages about racism have positive relationships with their children. In addition, preparation for bias has also been positively linked to racial-ethnic identity and self-esteem (Murry, Berkel, Brody, Miller, \& Chen, 2009), suggesting that preparation for bias is related to the PYD constructs of confidence, competence, and connection.

Future research might also examine relations of racial socialization with other aspects of connection and character. For example, discussions of the reality of racial discrimination may lead to a greater sense of connection to one's racial group. Sellers and Shelton (2003) found that racial identity is associated with increased reports of racial discrimination. It is likely, though, that these relationships are bidirectional-that discussions of discrimination lead to stronger racial identity. In addition, discussions of discrimination may lead to a sense of solidarity with other oppressed groups and to increases in civic engagement.

Egalitarian messages emphasize valuing individual characteristics rather than focusing primarily on racial group or avoiding conversations of race altogether (Hughes et al., 2006). This could include parents promoting cross-racial friendships in their children or exposing their children to the practices of other racial groups.

Although the literature on racial socialization has not focused on egalitarianism as widely as on other dimensions, recent studies have found relations with academic or cognitive outcomes (Banerjee, Harrell, \& Johnson, 2011; Neblett et al., 2006). For example, a longitudinal study of African American youth showed that parents who encouraged more cross-racial friendships had children with better cognitive competence in the form of verbal performance (Banerjee et al., 2011). These results demonstrate the positive effects of egalitarian socialization on cognitive competence. Other research has shown that children with more cross- racial friendships have better social skills, are better liked by peers, and have better psychosocial outcomes (Graham, Taylor, \& Ho, 2009). Future research might consider relations between egalitarianism and caring, confidence, and character. Socializing children to view all groups positively might lead to more openness to social differences and altruistic social behavior.

\section{CONCLUSION}

There is a small but growing body of research on positive outcomes among African American youth and families. However, given the abundance of research on negative outcomes or riskbased development, discerning a model of normative development for African Americans will require more theoretical and empirical knowledge of PYD. To acquire this knowledge, several adjustments are required for our programs of research regarding African American children and youth.

A primary concern is the use of "culture-neutral" models of youth development. Previous models of PYD have failed to appropriately attended to differences in context that may influence development. In particular, larger structural forces circumscribe African American children's opportunities for healthy development (Spencer et al., 2006). Nevertheless, PYD models fail to articulate the role of race and ethnicity for youth outcomes. Ginwright and Cammarota (2002) argue that psychological models of youth development assume growth at the individual level, which neglects the collective ecologies (such as sociohistorical expressions of oppression and racism) that shape the lives of youth of color. Thus, researchers must carefully consider the social stratification mechanisms that both foster and constrain developmental processes when developing PYD models for African American youth. Such deliberation may provide concrete guidance for the study of psychological competencies of African American youth and the collective assets of their communities.

Our review demonstrated that racial socialization is especially well related to competence and connection assets. The majority of the studies we reviewed touch on competence, a fairly mainstream developmental outcome. Future research must move beyond these traditional measures of success to include other aspects of PYD, such as civic engagement, prosocial behavior, future orientation, moral uprightness, and spirituality. Qualitative research from the 1980s and 1990s conducted with African American families showed that many African American mothers wanted their children to have self-respect and good moral character and, in turn, gave messages related to these values (Peters, 1985; Tatum, 1987). Furthermore, parents felt that it was important to provide love, security, and close personal relationships to their children to buffer the harmful effects of the racism in the dominant society.

In addition, researchers must look beyond communities and schools for information about contextual sites for positive development. Our review illustrates only one of the ways that African American families uniquely contribute to the process of 
positive development for their children. Other researchers have found that messages about religion, self-development, self-worth, or achievement surrounding race are important aspects of African American family life (Bowman \& Howard, 1985; LesaneBrown, Brown, Caldwell, \& Sellers, 2005; Stevenson, 1995). Our focus on racial socialization is meant to be a beginning, to encourage additional thinking about the development of PYD in African American families. Additional research, though, may consider other family processes. For example, many have noted the significant role of extended family in African American families (Billingsley, 1992) and have suggested that these relationships play a central role in maintaining the well-being of African American youth (e.g., Jones, Zalot, Foster, Sterret, \& Chester, 2006). As such, future studies on mechanisms of PYD in family contexts should examine how access to a wide range of invested adults might be an asset to African American youth.

As we consider the important role of families in fostering positive outcomes in African American children, we must also incorporate them in diverse social contexts. The current focus on resilience often locates the African American family in lowincome, underresourced, urban contexts with little examination of the functioning of middle-class African American families (Smetana \& Metzger, 2005), households with two parents (McHale et al., 2006), or those in rural and suburban settings (Murry et al., 2009).

Understanding the role of diverse contexts in fostering positive developmental outcomes also means understanding the differences in external assets that these contexts provide. Although some assets have stronger predictive utility for reports of positive outcomes, there is no "silver bullet." Because of the significance of child-environment interactions, a cumulative approach is necessary for fully understanding PYD (Leffert et al., 1998). A potential difficulty in conducting PYD research, though, is that the individual and ecological characteristics that may result in healthy outcomes are unique for each child. Resilience models do a good job of identifying how personal and contextual factors align to the benefit of youth development but have primarily centered on the personal assets of minority youth in negative contexts. Developmental research would benefit from a more balanced approach to identifying the internal and external factors that contribute to youth successes.

We are not advocating the use of research agendas that ignore the effects of negative contexts or factors that contribute to unhealthy development. Rather, we assert that perspectives on PYD should be more fully integrated into the current literature on African American youth. "For African American children and adolescents to develop into individuals actively engaged in optimal personal and collective development, they must be placed 'at promise' as opposed to 'at risk' (Boykin, 2000)" (American Psychological Association, Task Force on Resilience and Strength in Black Children and Adolescents, 2008, p. 3). Refining our definitions of what constitutes "positive" development is vital to distinguishing between resilience research and PYD.
Resilience is about surviving, not thriving. Focusing solely on problem-driven research keeps us from identifying the gifts and talents of youth who show no declines. By highlighting this distinction, we believe that our review provides a further step in narrowing definitions of PYD and advancing our understandings of youth development.

Expanding the current literature on African American youth by including examinations of PYD is important. As the notion of PYD grew out of fields such as community psychology, it is logical that the focus is on the role of community organizations and schools. However, families are also critical resources (Lerner et al., 2005). Although greater care has been taken to avoid research designs that imply deficits in African American families, there is still a need for exploration of the positive outcomes tied to parenting.

\section{REFERENCES}

American Psychological Association, Task Force on Resilience and Strength in Black Children and Adolescents. (2008). Resilience in African American children and adolescents: A vision for optimal development. Washington, DC: Author.

Banerjee, M., Harrell, Z. A. T., \& Johnson, D. J. (2011). Racial/ethnic socialization and parental involvement in education as predictors of cognitive ability and achievement in African American children. Journal of Youth and Adolescence, 40, 595-605.

Billingsley, A. (1992). Climbing Jacob's ladder: The enduring legacy of African-American families. New York: Simon \& Schuster.

Bowman, P. J., \& Howard, C. (1985). Race-related socialization, motivation and academic achievement: A study of Black youths in three-generation families. Journal of American Academy of Child Psychiatry, 24, 134-141.

Boykin, A. W. (2000). The talent development model of schooling: Placing students at promise for academic success. Journal of Education for Students Placed at Risk, 5(1 \& 2), 3-25.

Catalano, R., Berglund, M. L., Ryan, J. A. M., Lonczak, H., \& Hawkins, J. D. (2002). Positive youth development in the United States: Research findings on evaluations of positive youth development programs. Prevention \& Treatment, 5, 1-111.

Caughy, M. O., O'Campo, P. J., Randolph, S. M., \& Nickerson, K. (2002). The influence of racial socialization practices on the cognitive and behavioral competence of African American preschoolers. Child Development, 73, 1611-1625.

Ceballo, R., \& McLoyd, V. C. (2002). Social support and parenting in poor, dangerous neighborhoods. Child Development, 73, 13101321.

Checkoway, B. (2009). Community change for diverse democracy. Community Development Journal, 44, 5-21.

Damon, W. (2004). What is positive youth development? Annals of the American Academy of Political and Social Science, 59, 113-124.

Frabutt, J. M., Walker, A. M., \& MacKinnon-Lewis, C. (2002). Racial socialization messages and the quality of mother-child interactions in African American families. Journal of Early Adolescence, 22, 200-217.

Garcia Coll, C., Lamberty, G., Gontran, J., McAdoo, R., Pipes, H., Crnic, K., et al. (1996). An integrative model for the study of developmental competencies in minority children. Child Development, 67, 1891-1914. 
Ginwright, S., \& Cammarota, J. (2002). New terrain in youth development: The promise of a social justice approach. Crime and Social Justice, 29, 82.

Graham, S., Taylor, A. Z., \& Ho, A. Y. (2009). Race and ethnicity in peer relations research. In K. H. Rubin, W. M. Bukowski, \& B. Laursen (Eds.), Handbook of peer interactions, relationships, and groups (pp. 394-413). New York: Guilford.

Hagen, J. W., Pacynski, S. R., Sprang, C. B., Torvinen, B., \& Petiprin, M. (2010, March). Trends in published research on children versus adolescents: Race, ethnicity, and risk. Poster session presented at the biennial meeting of the Society for Research on Adolescence, Philadelphia, PA.

Harris-Britt, A., Valrie, C. R., Kurtz-Costes, B., \& Rowley, S. J. (2007). Perceived racial discrimination and self-esteem in African American youth: Racial socialization as a protective factor. Journal of Research on Adolescence, 17, 669-682.

Hughes, D., \& Chen, L. (1997). When and what parents tell children about race: An examination of race-related socialization among African American families. Applied Developmental Science, 1, 200-214.

Hughes, D., \& Johnson, D. J. (2001). Correlates in children's experiences of parents' racial socialization behaviors. Journal of Marriage and Family, 63, 981-995.

Hughes, D., Rodriguez, J., Smith, E. P., Johnson, D. J., Stevenson, H. C., \& Spicer, P. (2006). Parents' ethnic-racial socialization practices: A review of research and direction for future study. Developmental Psychology, 42, 747-770.

Hughes, D., Witherspoon, D., Rivas-Drake, D., \& West-Bey, N. (2009). Received ethnic-racial socialization messages and youths' academic and behavioral outcomes: Examining the mediating role of ethnic identity and self-esteem. Cultural Diversity and Ethnic Minority Psychology, 15, 112-124.

Jagers, R. J., Smith, P., Mock, L. O., \& Dill, E. (1997). An Afrocultural social ethos: Component orientations and some social implications. Journal of Black Psychology, 23, 328-343.

Jones, D. J., Zalot, A. A., Foster, S. E., Sterret, E., \& Chester, C. (2006). A review of childrearing in African American single mother families: The relevance of a coparenting framework. Journal of Child and Family Studies, 16, 671-683.

Larson, R. (2000). Toward a psychology of positive youth development. American Psychologist, 55, 170-183.

Leffert, N., Benson, P. L., Scales, P. C., Sharma, A. R., Drake, D. R., \& Blyth, D. A. (1998). Developmental assets: Measurement and prediction of risk behaviors among adolescents. Applied Developmental Science, 2, 209-230.

Lerner, R. M. (2004). Diversity in individual context relations as the basis for positive development across the lifespan: A developmental systems perspective for theory, research, and application. Research in Human Development, 1, 327-346.

Lerner, R. M., Lerner, J. V., Almerigi, J. B., Theokas, C., Phelps, E., Gestsdottir, S., et al. (2005). Positive youth development, participation in community youth development programs, and community contributions of fifth-grade adolescents: Findings from the first wave of the 4-H study of positive youth development. Journal of Early Adolescence, 1, 17-71.

Lesane-Brown, C. L., Brown, T. N., Caldwell, C. H., \& Sellers, R. M. (2005). The comprehensive race socialization inventory. Journal of Black Studies, 36, 163-190.

Marshall, S. (1995). Ethnic socialization of African American children: Implications for parenting, identity development and academic achievement. Journal of Youth and Adolescence, 24, 377-396.
Masten, A. S., \& Coatsworth, J. D. (1998). The development of competence in favorable and unfavorable environments: Lessons from research on successful children. American Psychologist, 53, 205-220.

Maton, K. I., Hrabowski, F. A., \& Greif, G. L. (1998). Preparing the way: A qualitative study of high achieving African American males and the role of the family. American Journal of Community Psychology, 26, 639-668.

McAdoo, H. P. (1999). Family ethnicity: Strength in diversity. Thousand Oaks, CA: Sage.

McHale, S., Crouter, A., Kim, J., Burton, L., Davis, K., Dotterer, E., et al. (2006). Mothers' and fathers' racial socialization in African American families: Implications for youth. Child Development, 77, 1387-1402.

McLoyd, V. C. (1990). The impact of economic hardship on Black families and children: Psychological distress, parenting, and socioemotional development. Child Development, 61, 311-346.

McLoyd, V. C. (2006). The legacy of Child Development's 1990 special issue on minority children: An editorial retrospective. Child Development, 77, 1142-1148.

McLoyd, V. C., \& Randolph, S. (1985). Secular trends in the study of Afro-American children: A review of Child Development. In A. B. Smuts \& J. W. Hagen (Eds.), History and research in child development. Monographs of the Society for Research on Child Development, 50(4-5, Serial No. 211).

Morrissey, K. M., \& Werner-Wilson, R. J. (2005). The relationship between out-of-school activities and positive youth development: An investigation of the influences of communities and family. Adolescence, 40, 67-85.

Murry, V. M., Berkel, C., Brody, G. H., Miller, S. J., \& Chen, Y. (2009). Linking parental socialization to interpersonal protective processes, academic self-presentation, and expectations among rural African American youth. Cultural Diversity and Ethnic Minority Psychology, 15, 1-10.

Nagda, B. A. (2006). Breaking barriers, crossing borders, building bridges: Communication processes in intergroup dialogues. Journal of Social Issues, 62, 553-576.

Neblett, E. W., Philip, C. L., Cogburn, C. D., \& Sellers, R. M. (2006). African American adolescents' discrimination experiences and academic achievement: Racial socialization as a cultural compensatory and protective factor. Journal of Black Psychology, 32, 199-218.

Neblett, E., Smalls, C., Ford, K., Nguyên, H., \& Sellers, R. (2009). Racial socialization and racial identity: African American parents' messages about race as precursors to identity. Journal of Youth and Adolescence, 38, 189-203.

Peters, M. F. (1985). Racial socialization of young Black children. In H. P. McAdoo \& J. L. McAdoo (Eds.), Black children: Social, educational and parental environments (pp. 159-173). Beverly Hills, CA: Sage.

Roth, J. L., \& Brooks-Gunn, J. (2003). Youth development programs: Risk, prevention and policy. Journal of Adolescent Health, 32, 170-182.

Rowley, S. J., Sellers, R. M., Chavous, T. M., \& Smith, M. A. (1998). The relationship between racial identity and self-esteem in African American college and high school students. Journal of Personality and Social Psychology, 74, 715-724.

Sanders, M. G. (1997). Overcoming obstacles: Academic achievement as a response to racism and discrimination. Journal of Negro Education, 66, 83-93. 
Scales, P. C., Benson, P. L., Leffert, N., \& Blyth, D. A. (2000). Contribution of developmental assets to the prediction of thriving among adolescents. Applied Developmental Science, 4, 27-46.

Sellers, R. M., Copeland-Linder, N., Martin, P. M., \& Lewis, L. (2006). Racial identity matters: The relationship between racial discrimination and psychological functioning in African American adolescents. Journal of Research on Adolescence, 16, 187-216.

Sellers, R. M., \& Shelton, J. N. (2003). The role of racial identity in perceived racial discrimination. Journal of Personality and Social Psychology, 84, 1079-1092.

Smetana, J. G., \& Metzger, A. (2005). Family and religious antecedents of civic involvement in middle class African American adolescents. Journal of Research on Adolescence, 15, 325-352.

Spencer, M. S., Brown, M., Griffin, S., \& Abdullah, S. (2008). Outcome evaluation of the intergroup project. Small Group Research, 39, 82103.

Spencer, M. B., Harpalani, V., Cassidy, E., Jacobs, C. Y., Donde, S., \& Goss, T. N. (2006). Understanding vulnerability and resilience from a normative developmental perspective: Implications for racially and ethnically diverse youth. In D. Cicchetti \& D. J. Cohen
(Eds.), Developmental psychopathology: Vol. 1. Theory and method (2nd ed., pp. 627-672). Hoboken, NJ: Wiley.

Stevenson, H. C. (1995). Relationship to adolescent perceptions of racial socialization to racial identity. Journal of Black Psychology, 21, 49-70.

Suizzo, M. A., Robinson, C., \& Pahlke, E. (2008). African American mothers' socialization beliefs and goals with young children: Themes of history, education and collective independence. Journal of Family Issues, 29, 287-316.

Tatum, B. D. (1987). Assimilation blues: Black families in a White community. Westport, CT: Greenwood.

Taylor, L. C. (2001). Work attitudes, employment barriers and mental health symptoms in a sample of rural welfare recipients. American Journal of Community Psychology, 29, 443-463.

Tolan, P. H., Sherrod, L. R., Gorman-Smith, D., \& Henry, D. B. (2004). Building protection, support and opportunity for inner-city children and youth and their families. In K. I. Maton, C. J. Schellenbach, B. J. Leadbeater, \& A. L. Solarz (Eds.), Investing in children, youth, families and communities: Strengths-based research and policy (pp. 193-211). Washington, DC: American Psychological Association. 